\title{
Isomerization Polymerization of 2-Oxazoline. II. Propagating Species and Mechanism of Unsubstituted 2-Oxazoline Polymerization
}

\author{
Takeo SAegusa, Hiroharu Ikeda, and Hiroyasu FujiI \\ Department of Synthetic Chemistry, Kyoto University, \\ Kyoto, Japan.
}

(Received June 4, 1971)

\begin{abstract}
The propagating species and the mechanism of the cationic polymerization of 2-oxazoline(OXZ) were investigated. Equimolar reactions of OXZ with polymerization catalysts were directly followed by NMR spectra. In the polymerization with methyl tosylate(MeOTs) catalyst, the propagating species was shown to be an oxazolinium ion. In the reaction of $\mathrm{OXZ}$ with $\mathrm{BF}_{3} \mathrm{OEt}_{2}$ in acetonitrile at $40^{\circ} \mathrm{C}$, the $\mathrm{BF}_{3}-\mathrm{OXZ}$ complex was isolated in a quantitative yield. On the other hand, in the reaction of $\mathrm{OXZ}$ with $\mathrm{CH}_{3} \mathrm{I}$ at $80^{\circ} \mathrm{C}$, no oxazolinium ion was detected, but $N$-( $\beta$-iodoethyl)- $N$-methylformamide 3 was isolated. 3 was taken to have been derived from the ring-opening reaction of unstable oxazolinium iodide which was transiently formed by the reaction of $\mathrm{OXZ}$ with $\mathrm{CH}_{3} \mathrm{I}$. In addition, 3 itself caused the $\mathrm{OXZ}$ polymerization and gave a similar polymer yield to that of the polymerization by $\mathrm{CH}_{3} \mathrm{I}$. Thus, the propagating species of the $\mathrm{OXZ}$ polymerization by $\mathrm{CH}_{3} \mathrm{I}$ was assumed to be $\mathrm{N}(\mathrm{CHO}) \mathrm{CH}_{2} \mathrm{CH}_{2} \mathrm{~N}(\mathrm{CHO}) \mathrm{CH}_{2} \mathrm{CH}_{2} \mathrm{I}$. The initiating behavior of alkyl halides and the effect of solvents upon the $\mathrm{OXZ}$ polymerization demonstrated a close-relationship between the OXZ polymerization by alkyl halide catalyst and the Menschutkin reaction.

KEY WORDS 2-Oxazoline / Cationic Polymerization / Poly $(N$-formylethyleneimine) / Propagating Species / Oxazolinium Ion / $N-(\beta-$ iodoethyl)- $N$-methylformamide / Menschutkin Reaction /
\end{abstract}

Cationic polymerization of 2-substituted-2oxazolines has been widely studied, ${ }^{1-4}$ and the following schemes involving the oxazolinium ion has been assumed without direct experimental support.
On the other hand, the polymerization of unsubstituted 2-oxazoline(OXZ) was not reported before our recent paper. ${ }^{5}$ We first succeded in the cationic polymerization of OXZ by the isolation of the pure monomer and the use of<smiles>[R]C1=NCCO1</smiles> 
aprotic solvents such as dimethylformamide (DMF) and acetonitrile as the polymerization medium. ${ }^{5}$ The $\mathrm{OXZ}$ polymer is crystalline and has a structure of poly $(N$-formylethyleneimine $){ }^{5}$

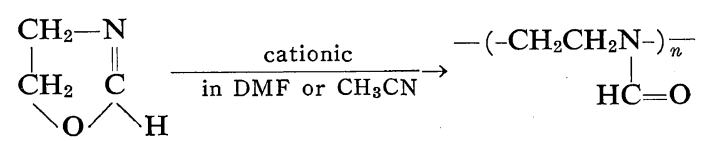

In the present studies, the nature of the propagating species and the mechanism of the OXZ polymerization intiated by several catalysts were examined on the basis of the equimolar reaction of $\mathrm{OXZ}$ with the polymerization catalysts.

\section{EXPERIMENTAL}

\section{Reagents}

$\mathrm{OXZ}$ was prepared and purified as before. ${ }^{5}$ $\mathrm{BF}_{3} \mathrm{OEt}_{2}, \mathrm{CH}_{3} \mathrm{I}$, and methyl tosylate(MeOTs) were purified by distillation under nitrogen. DMF and acetonitrile were purified by distillation under nitrogen and dried by molecular sieves 4A. Commercial reagent of acetonitrile$d_{3}\left(\mathrm{CD}_{3} \mathrm{CN}\right)$ was dried by molecular sieves $4 \mathrm{~A}$ and distilled under nitrogen.

\section{Polymerization}

Polymerization was carried out in a glass tube under nitrogen. Firstly, the catalyst was added to a mixture of monomer and solvent at $0^{\circ} \mathrm{C}$ in a tube, and then the tube was sealed and heated. After polymerization methanol was added to the reaction mixture, and the precipitated polymer was isolated by filtration and dried in vacuo. The washings were evaporated under reduced pressure and an oily oligomer was obtained as the residue.

\section{Equimolar Reaction of $O X Z$ with Catalyst}

All operations were carried out under nitrogen. NMR Study. The desired amount of catalyst was slowly added to a stirred solution of monomer in $\mathrm{CD}_{3} \mathrm{CN}$ which had been cooled to $-30^{\circ} \mathrm{C}$. Then the mixture was kept at a constant temperature. After the reaction, the reaction mixture was immediately subjected to NMR measurement.

Reaction of $\mathrm{OXZ}$ with $\mathrm{BF}_{3} \mathrm{OEt}_{2}$. To a solution of $7.5 \mathrm{mmol}$ of $\mathrm{OXZ}$ in $3 \mathrm{ml}$ of $\mathrm{CH}_{3} \mathrm{CN}$ was added $7.5 \mathrm{mmol}$ of $\mathrm{BF}_{3} \mathrm{OEt}_{2}$ at $-30^{\circ} \mathrm{C}$ with stirring. The mixture was stirred at $40^{\circ} \mathrm{C}$ for $10 \mathrm{~min}$. Then the evaporation of solvent under a reduced pressure gave a crystalline powder. The material was reprecipitated from the acetonitrile solution by ether to yield $1.02 \mathrm{~g}(98 \%)$ of crystalline powder: IR (Nujol) $1662(\mathrm{C}=\mathrm{N}-$ ) $1218(\mathrm{C}-\mathrm{O}-\mathrm{C})$, and $902,867,863 \mathrm{~cm}^{-1}$ (skeletal); $\mathrm{NMR}\left(\mathrm{CD}_{3} \mathrm{CN}\right) \tau 2.08(\mathrm{~s}, 1, \mathrm{~N}=\mathrm{CH}-), 5.15$ (t, 2, $\left.-\mathrm{CH}_{2}-\mathrm{O}\right)$, and $6.07 \mathrm{ppm}\left(\mathrm{t}, 2,-\mathrm{CH}_{2}-\mathrm{N}\right)$. Reaction of $\mathrm{OXZ}$ with $\mathrm{CH}_{3} I$. In a glass tube, $60 \mathrm{mmol}$ of $\mathrm{CH}_{3} \mathrm{I}$ was added at $0^{\circ} \mathrm{C}$ with stirring to a $60 \mathrm{mmol}$ of $\mathrm{OXZ}$ in $10 \mathrm{ml}$ of acetonitrile. Then the solution was stirred at $80^{\circ} \mathrm{C}$ for 10 min in a sealed tube. By GLPC and NMR analyses, the conversion of $\mathrm{OXZ}$ was found to be quantitative and that of $\mathrm{CH}_{3} \mathrm{I}$ was $81 \%$.

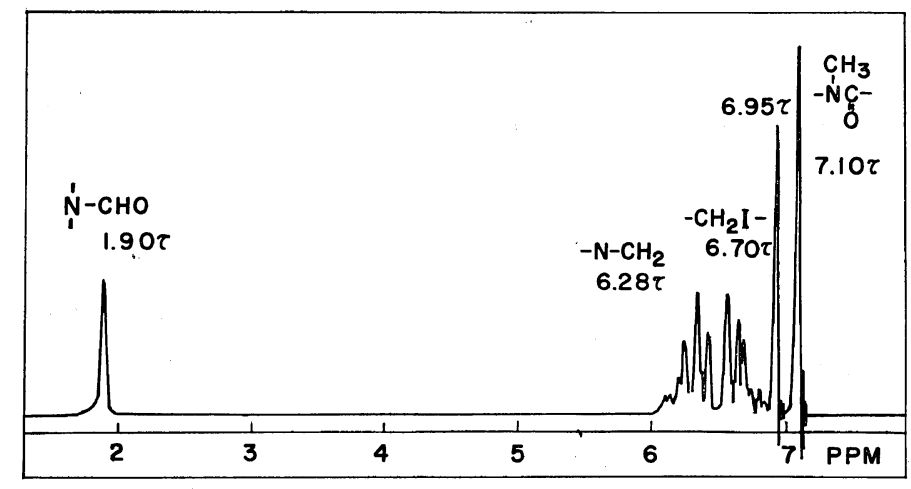

Figure 1. NMR spectrum of $\mathrm{ICH}_{2} \mathrm{CH}_{2} \mathrm{NCHO} 3$ (in $\mathrm{CHCl}_{3}$ ).<smiles>C1CC1</smiles> 
After the solvent and $\mathrm{CH}_{3} \mathrm{I}$ were removed under vacuum at room temperature, the residue was extracted twice with $20 \mathrm{ml}$ of anhydrous ether. The ether extract was distilled to give $6.47 \mathrm{~g}$ $(30.4 \mathrm{mmol}, 51 \%)$ of a fraction boiling at $67-$ $74^{\circ} \mathrm{C}(0.1 \mathrm{~mm})$, which was identified at $N-(\beta-$ iodoethyl)- $N$-methylformamide 3. Anal. Calcd for $\mathrm{C}_{4} \mathrm{H}_{8} \mathrm{INO}: \mathrm{C}, 22.55 ; \mathrm{H}, 3.79 ; \mathrm{I}, 59.58 ; \mathrm{N}$, 6.58; O, 7.51: mol wt, 213. Found: C, 22.49; H, 3.93; I, 59.67; N, 6.89; O, 7.68: mol wt, 213 (mass spectroscopy), NMR (Figure 1, $\mathrm{CDCl}_{3}$ ) agreed well with that of the authentic sample. The ether insoluble part was a reddish oil (3.32 g), which was shown by NMR to be a mixture of the OXZ oligomers.

\section{Preparation of $N$-( $\beta$-chloroethyl)- $N$-methylform- amide 4}

4 was prepared by the reaction of $N$ - $(\beta$-hydroxyethyl)- $N$-methylformamide with thionyl chloride/pyridine in $\mathrm{CHCl}_{3}$ : yield $65 \%$; bp 97.5 ${ }^{\circ} \mathrm{C}(3 \mathrm{~mm})$; NMR $\left(\mathrm{CDCl}_{3}\right) \tau 1.92$ (s, 1, CHO), $6.32\left(\mathrm{~m}, 4, \mathrm{CH}_{2}\right)$, and 6.99 (d, 3, $\left.\mathrm{NC}_{3}\right)$. Anal. Calcd for $\mathrm{C}_{4} \mathrm{H}_{8} \mathrm{ClNO}$ : C, 39.52; $\mathrm{H}, 6.63 ; \mathrm{Cl}$, 29.16; N, 11.52. Found: C, 39.23; H, 6.91; Cl, 29.29; N, 11.40 .

\section{Preparation of $N$-( $\beta$-iodoethyl $)-N$-methylformamide 3}

3 was prepared by the reaction of 4 with $\mathrm{NaI}$ in acetone. The product was a slightly yellow liquid: yield $25 \%$; bp $89^{\circ} \mathrm{C}(0.2 \mathrm{~mm})$; IR 1667 $\mathrm{cm}^{-1}$ (amide $\mathrm{C}=\mathrm{O}$ ); $\mathrm{NMR}\left(\mathrm{CDCl}_{3}\right) \tau 1.90$ (s, 1 , Cㅂㅇ), $6.28\left(\mathrm{~m}, 2, \underline{\mathrm{CH}}_{2} \mathrm{~N}\right), 6.70\left(\mathrm{~m}, 2, \mathrm{C}_{2} \mathrm{I}\right)$, and $7.03\left(\mathrm{~d}, 3, \mathrm{CH}_{3} \mathrm{~N}\right)$; Anal. Calcd for $\mathrm{C}_{4} \mathrm{H}_{3} \mathrm{INO}$ : $\mathrm{C}, 22.55, \mathrm{H}, 3.79 ; \mathrm{I}, 59.58 ; \mathrm{N}, 6.85 ; \mathrm{O}, 7.51$; mol wt, 213. Found: C, 22.62; H, 3.86; I, 58.74; $\mathrm{N}, 7.04 ; \mathrm{O} ; 7.87$; mol wt, 213 (mass spectroscopy).

\section{NMR Spectroscopy}

NMR spectra were taken on Varian T-60 instrument using TMS as internal standard.

\section{Molecular Weight}

The molecular weight of the polymer was measured using a vapor pressure osmometer (Hitachi-Perkin-Elmer model 115) in water at $59^{\circ} \mathrm{C}$.

\section{RESULTS AND DISCUSSION}

Equimolar reactions of $\mathrm{OXZ}$ with several polymerization catalysts ${ }^{5}$ were carried out in order to identify the real propagating species and to examine the polymerization mechanism.

\section{Reaction of $O X Z$ with MeOTs}

An equimolar reaction mixture of $\mathrm{OXZ}$ with MeOTs in $\mathrm{CD}_{3} \mathrm{CN}$ at $60^{\circ} \mathrm{C}$ for $10 \mathrm{~min}$ was examined by NMR spectrum (Figure 2). The peaks assignable to the oxazolinium salt were observed. In addition, the absorption peaks of oxazolinium tosylate were distinguished from the corresponding peaks of the unreacted OXZ and MeOTs. Therefore, the concentrations of the species in the reaction mixture were successfully determined. The percent conversion of the catalyst was $26 \%$, which was calculated from

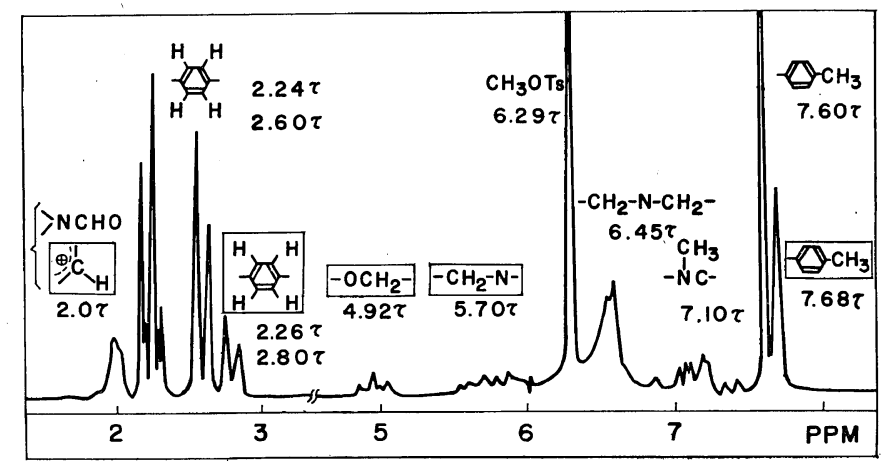

Figure 2. NMR spectrum of equimolar reaction of oxazoline with methyl tosylate in $\mathrm{CD}_{3} \mathrm{CN}$ at $60^{\circ} \mathrm{C}$ : oxazoline, $2.29 \mathrm{~mol} / l$; methyl tosylate, $2.29 \mathrm{~mol} / \mathrm{l}$. The groups in rectangles are those of the oxazolinium salt. 
the peaks at $\tau 2.80\left(-<-\mathrm{CH}_{3}\right.$ of reacted

$\mathrm{MeOTs}$ ) and $\tau 2.60$ (unreacted MeOTs). The conversion of monomer was shown to be quantitative. No peak of monomer was observed and the peak area at $\tau 2.0=\mathrm{NCHO}-$ of oxazolinium salt and the formyl hydrogen, coincided with the stoichiometric amount of the fed monomer. The peak at $\tau 4.92$ was reasonably assigned to the $O$-methylene protons of the oxazolinium ion at the growing polymer end, since the peaks of $O$-methylene protons of the oxazolinium salts derived from the reactions of 2-methyl- and 2phenyl-2-oxazolines with MeOTs in ether, have appeared at similar regions $(\tau 5.20$ and $4.93 \mathrm{ppm}$, at $80^{\circ} \mathrm{C}$, no oxazolinium ion was observed. Instead, 3 was obtained as the main product (conversion 51\%). The structure of 3 was established by comparing the analytical data with those of an authentic sample prepared by a separate method (see Experimental section). The other product of this reaction was a linear oligomer of OXZ. These results suggest that in the reaction of $\mathrm{OXZ}$ with $\mathrm{CH}_{3} \mathrm{I}, N$-methyloxazolinium iodide 7 was transiently formed as an unstable intermediate, which was instantaneously converted to $\mathbf{3}$ by the ring-opening with isomerization. The oligomer 8 was formed by the repetition of the same type of process.

In an equimolar reaction at a lower temperature of $60^{\circ} \mathrm{C}$, oxazolinium salt was not observed, either, in spite of the presence of a fairly

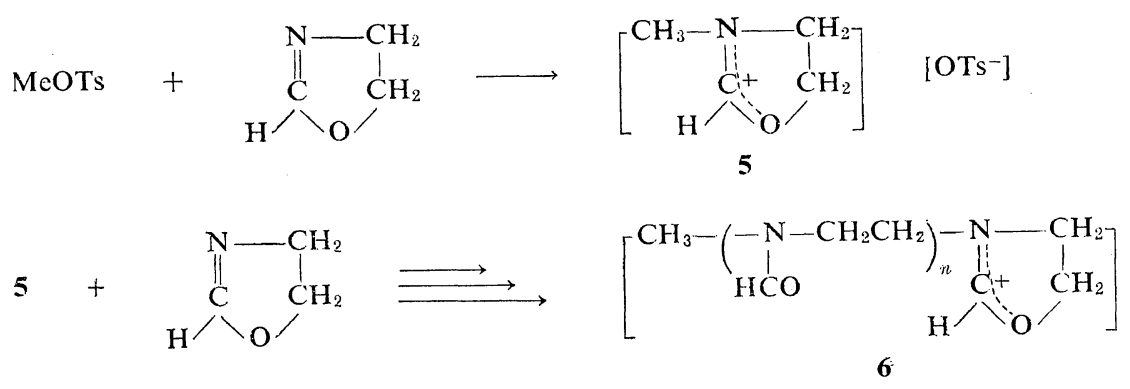

large amount of unreacted monomer (conversion $41 \%)$.

\section{Polymerization by Alkyl Halide Initiators}

The polymerization of OXZ was carried out using $\mathbf{3}$ as well as various alkyl halide initiators. The results are shown in Table I. 3 gave a similar yield of polymer to that of polymerization by $\mathrm{CH}_{3} \mathrm{I}$. This fact supports the above assumption regarding the mechanism. No catalytic activity, however, was shown with 4 , which was the chlorine analogue of 3. Similarly, butyl iodide was found to be active as catalyst, but butyl bromide showed much decreased activity and butyl chloride showed no catalytic activity at all.

Thus the species having the structure of $\sim \mathrm{N}(\mathrm{CHO}) \mathrm{CH}_{2} \mathrm{CH}_{2} \mathrm{I}$ are taken to be the propagating species of the $\mathrm{OXZ}$ polymerization by $\mathrm{CH}_{3} \mathrm{I}$ catalyst. 


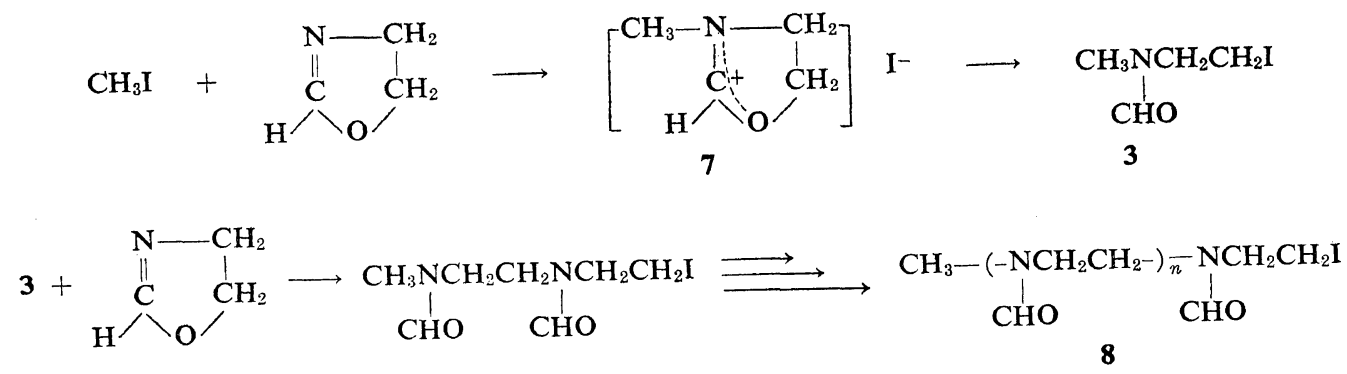

This finding provides a striking contrast to the equimolar reaction of 2-methyl-2-oxazoline with $\mathrm{CH}_{3} \mathrm{I}$, in which the formation of a considerable amount of the 2-methyl oxazolinium iodide species was suggested ${ }^{7}$ and observed by NMR. ${ }^{6}$

As to the effect of the solvent, the use of toluene instead of acetonitrile resulted in a poor yield, as observed in the polymerization by $\mathrm{BF}_{3} \mathrm{OEt}_{2} .^{5}$

Table I. Polymerization of 2-oxazoline by alkyl halides ${ }^{a}$

\begin{tabular}{lc}
\hline \multicolumn{1}{c}{ Alkyl halides } & Polymer yield, \% \\
\hline $\mathrm{CH}_{3} \mathrm{I}$ & 30 \\
$\mathrm{HCON}\left(\mathrm{CH}_{3}\right) \mathrm{CH}_{2} \mathrm{CH}_{2} \mathrm{I}$ & 24 \\
$\mathrm{HCON}\left(\mathrm{CH}_{3}, \mathrm{CH}_{2} \mathrm{CH}_{2} \mathrm{Cl}\right.$ & 0 \\
$n-\mathrm{C}_{4} \mathrm{H}_{9} \mathrm{I}$ & 18 \\
$n-\mathrm{C}_{4} \mathrm{H}_{9} \mathrm{Br}$ & 6.6 \\
$n-\mathrm{C}_{4} \mathrm{H}_{9} \mathrm{Cl}$ & 0 \\
$\mathrm{CH}_{3} \mathrm{I}^{\mathrm{b}}$ & 4.0 \\
\hline a 2-oxazoline, 3.2 mol/l; catalyst, & $0.032 \mathrm{~mol} / l ;$ \\
$\quad$ solvent, $\mathrm{CH}_{3} \mathrm{CN} ; 80^{\circ} \mathrm{C}, 5 \mathrm{hr}$. \\
b Solvent, toluene.
\end{tabular}

All these reactions are interestingly compared with the reactivities of alkyl halides and the solvent effect in the Menschutkin reaction ${ }^{8,9}$ in which quarternary ammonium salt is formed by the reaction of tertiary amine with alkyl halide.

$$
\mathrm{R}_{3} \mathrm{~N}+\mathrm{RX} \longrightarrow \mathrm{R}_{4} \mathrm{X}
$$

The reactivities of alkyl halides in the Menschutkin reaction have been shown to decrease in the order $\mathrm{RI}>\mathrm{RBr} \gg \mathrm{RCl}$. In addition, the reaction rate was much influenced by the nature of the solvent. For example, in the re- action of $\mathrm{Et}_{3} \mathrm{~N}$ with EtI, the rate constants at $70^{\circ} \mathrm{C}$ were in a ratio of $3.6: 16: 188$ in toluene, ether, and benzonitrile, respectively. These observations suggest the similarity in the mechanism of this reaction to alkyl halide-catalyzed polymerization of OXZ.

Reaction of $\mathrm{OXZ}$ with $\mathrm{BF}_{3} \mathrm{OEt}_{2}$

A crystalline $\mathrm{OXZ}-\mathrm{BF}_{3}$ complex was isolated in a quantitative yield from an equimolar reaction of $\mathrm{OXZ}$ with $\mathrm{BF}_{3} \mathrm{OEt}_{2}$ in $\mathrm{CH}_{3} \mathrm{CN}$ at 40 ${ }^{\circ} \mathrm{C}$, which was suggested by its NMR and IR spectra, and no other product was observed in the NMR spectrum search of the reaction mixture. Even when another equimolar amount of $\mathrm{OXZ}$ was added to the $\mathrm{OXZ}-\mathrm{BF}_{3}$ complex at $40^{\circ} \mathrm{C}$, no reaction took place. But the reaction at $60^{\circ} \mathrm{C}$ gave a large amount of polymer. The initiating and propagating species of this case have not been examined.

\section{REFERENCES}

1. A. Tomalia and D. P. Sheetz, J. Polym. Sci., Part A-1, 4, 2253 (1966).

2. W. Seeliger, Angew. Chem., 78, 613 (1966); 78, 913 (1966).

3. T. Kagiya, S. Narisawa, T. Maeda, and $\mathrm{K}$. Fukui, Polym. Lett., 4, 441 (1966).

4. T. G. Bassiri, A. Levy, and M. Litt, Polym. Lett., 5, 871 (1967).

5. T. Saegusa, H. Ikeda, and H. Fujii, Polymer. $J$. to be published.

6. T. Saegusa, H. Ikeda, and H. Fujii, to be published.

7. Kodak Ltd. Co., Brit. Patent 541330 (1941).

8. N. Menschutkin, Z. Phys. Chem., 5, 589 (1890); ibid, 6, 41 (1890).

9. H. G. Grimn, H. Ruf, and H. Wolff, Z. Phys. Chem. Abt. B. Bd. 13, 301 (1931). 